\title{
Produtividade, fitotoxicidade e controle de arroz-vermelho na sucessão de cultivo de arroz irrigado no Sistema CLEARFIELD ${ }^{\circledast}$
}

\author{
Productivity, injury and control of red rice in succession of irrigated rice \\ cultivation in System CLEARFIELD ${ }^{\circledast}$
}

\section{Enio Marchesan ${ }^{\mathrm{I}}$ Paulo Fabricio Sachet Massoni" ${ }^{\mathrm{II}}$ Silvio Carlos Cazarotto Villa ${ }^{\mathrm{II}}$ Mara Grohs ${ }^{\mathrm{II}}$ Luis Antonio de Avila ${ }^{\text {IV }}$ Gerson Meneghetti Sarzi Sartori ${ }^{\text {II }}$ Rafael Ferreira Bruck ${ }^{\text {II }}$}

\section{RESUMO}

\begin{abstract}
$O$ objetivo deste trabalho foi avaliar o sistema CLEARFIELD ${ }^{\circledR}$ quanto ao controle do arroz-vermelho, influência sobre a produtividade, bem como a fitotoxicidade ocasionada pelo possivel residual no solo da mistura formulada de imazethapyr e imazapic em genótipo de arroz tolerante (IRGA 422CL) e não-tolerante (IRGA 417), os quais serviram como plantas indicadoras. $O$ delineamento experimental foi de blocos ao acaso em esquema bifatorial (4x3) com parcelas subdivididas, sendo as parcelas principais representadas pela rotação entre arroz tolerante (IRGA 422CL) e o arroz nãotolerante a imidazolinonas (IRGA 417). Nas sub-parcelas foram aplicados os tratamentos para o controle de arroz-vermelho em diferentes épocas de aplicação (pós-emergência (V4), pré+ pós emergência (no dia da semeadura $+V 4$ ). A fitotoxicidade foi caracterizada com base na cor das folhas, largura, crescimento e desenvolvimento do limbo foliar. Observou-se que a fitotoxicidade foi maior quando o herbicida foi aplicado em pós-emergência permanecendo seus efeitos até 383 dias após a aplicação. $O$ controle de arroz-vermelho não é eficiente com a utilização de apenas um ano agrícola do sistema CLEARFIELD ${ }^{\circledR}$ e o melhor nivel de controle e produtividade foi obtido após dois ou três anos consecutivos desse sistema.
\end{abstract}

Palavras-chave: imazethapyr, planta daninha, residual.

\section{ABSTRACT}

The objective of this study was to evaluate the CLEARFIELD ${ }^{\circledR}$ system regarding the control of red rice, influences on productivity, as well as the possible phytotoxicity caused by carryover soil formulated mixture of imazethapyr and imazapic in tolerant rice genotype (IRGA 422CL) and non-tolerant (IRGA 417), which served as indicator plants. The experimental design was randomized blocks in a factorial scheme (4x3) with subplots, the main plots represented by rotating tolerant rice (IRGA 422CL) and rice not tolerant to imidazolinone (IRGA 417). In sub-plot treatments were applied to control red rice in different stages of the post-emergence (V4), pre + post emergence (day of seeding V4). Phytotoxicity was characterized based on the color of the leaves, width, growth and development of the leaf. It was observed that phytotoxicity was greater when the herbicide was applied post-emergence, effects remaining until 383 days after application. The control of red rice is not efficient with the use of only one agricultural year of CLEARFIELD ${ }^{\circledR}$ system and the best level of control and yield was obtained after two or three consecutive years of this system.

Key words: imazethapyr, weed, carryover.

\section{INTRODUÇÃO}

Em decorrência da elevada infestação das lavouras de arroz irrigado por arroz-vermelho, novas tecnologias de controle químico tem sido desenvolvidas para o controle dessa planta daninha, responsável pela redução de produtividade do arroz bem como pela depreciação do valor do produto final. $\mathrm{O}$ desenvolvimento de genótipos tolerantes a herbicidas do grupo químico das imidazolinonas, tecnologia denominada sistema CLEARFIELD ${ }^{\circledR}$, tornou-se uma ferramenta eficiente para o manejo do

'Departamento de Fitotecnia, Centro de Ciências Rurais (CCR), Universidade Federal de Santa Maria (UFSM), 97105-900, Santa Maria, RS, Brasil. E-mail: emarchezan@terra.com.br*Autor para correspondência.

"Departamento de Fitotecnia, UFSM, Santa Maria, RS, Brasil.

"II'Rice tec Sementes Ltda. Porto Alegre, RS, Brasil.

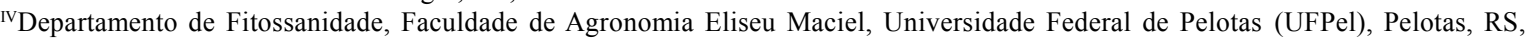
Brasil. 
arroz-vermelho, permitindo aos agricultores o controle seletivo. No Brasil, essa alternativa consiste na aplicação da mistura formulada de $75 \mathrm{~g}$ i.a. $\mathrm{L}^{-1}$ de imazethapyr $+25 \mathrm{~g}$ i.a. $\mathrm{L}^{-1}$ de imazapic em genótipo de arroz tolerante (IRGA 422CL), sendo recomendada a dose de $1,0 \mathrm{~L} \mathrm{ha}^{-1}$ do produto comercial $\left(\right.$ Only ${ }^{\circledR}$ ), aplicado em pós-emergência (POS) quando as plantas se encontram no estádio fenológico V4 pela escala de COUNCE (2000). Contudo, as conseqüências dessa utilização muitas vezes não são mensuradas e os impactos ambientais decorrentes são ainda pouco conhecidos. A utilização de culturas de inverno como pastagens na rotação lavoura/pecuária ou a escolha de genótipos de arroz não-tolerantes podem ser afetadas pela biodisponibilidade de resíduos desses herbicidas no solo. Os danos, em sua maioria, podem ser observados visualmente e, dependendo de seu grau, podem causar até morte de plantas ou redução na produtividade.

A persistência no solo de herbicidas do grupo químico das imidazolinonas, ao qual pertencem o imazapic, imazapyr, imazamox, imazethabenz e imazethapyr, é influenciada por propriedades que vão além da textura do solo, tais como pH (LOUX \& REESE, 1992), umidade (BAUGHMAN \& SHAW, 1996), matéria orgânica (STOUGAARD et al., 1990) e concentração de oxigênio (aerobiose/anaerobiose)(KRAEMER et al., 2009a).

Os herbicidas imazethapyr e imazapic são persistentes no solo e a dissipação ocorre através da fotólise e degradação microbiana (ALISTER \& KOGAN, 2005). Alguns estudos e observações de campo indicam que os principais fatores determinantes da persistência destes herbicidas no ambiente estão diretamente associados a condições de clima e solo tais como drenagem, preparo do solo, teor de argila no solo e temperatura (KRAEMER et al. 2009a). Desta forma estas condições de clima e solo são relacionadas às práticas de manejo do solo (PEREZ et al. 2005). Além disso, resíduos do herbicida podem ser arrastados pela chuva ou pela água de irrigação e atingir o lençol freático ou os lençóis superficiais, causando prejuízos ao ambiente (CLAY, 1993).

Neste sentido, recomenda-se intervalos de segurança entre a aplicação de herbicidas e a implantação de culturas não-tolerantes em decorrência das injúrias provocadas nas plantas. Para as imidazolinonas, a maioria das recomendações de intervalo de segurança baseia-se em estudos realizados nos Estados Unidos e na Europa, onde podem variar de 31 a 410 dias para imazapic (GRYMES, 1995) ou até 436 dias para imazapyr (COX, 1996) para culturas de sequeiro, onde as condições edafoclimáticas são diferentes das encontradas no Brasil, e em especial em solos de várzea. Estudos que avaliem o potencial residual no solo dos herbicidas aplicados na lavoura de arroz sob as condições edafoclimáticas brasileiras fazem-se necessários para o desenvolvimento de estratégias de manejo para a rotação com culturas nãotolerantes.

Nesse sentido, o presente trabalho teve como objetivo avaliar o sistema CLEARFIELD ${ }^{\circledR}$ quanto ao controle do arroz-vermelho, influência sobre a produtividade do arroz, bem como a fitotoxicidade ocasionada pelo residual no solo da mistura formulada de imazethapyr e imazapic, estimada através de plantas indicadoras, genótipo de arroz tolerante (IRGA 422CL) e não-tolerante (IRGA 417) .

\section{MATERIAL E MÉTODOS}

O experimento foi conduzido nos anos agrícolas de 2004/05, 2005/06 e 2006/07, em solo classificado como Planossolo Háplico eutrófico arênico (EMBRAPA, 2006) com as seguintes características químicas: $\mathrm{pH}_{\text {água }}(1: 1): 5,0 ; \mathrm{P}: 8,0 \mathrm{mg} \mathrm{dm}^{-3} ; \mathrm{K}: 32 \mathrm{mg} \mathrm{dm}^{-3}$; argila: $20 \%$; silte: $68 \%$; areia: $12 \%$; M.O.: 1,6\%; Ca: 3,3 $\mathrm{cmolc} \mathrm{dm}^{-3}$; Mg: 1,0 cmolc dm ${ }^{-3}$ e Al: 0,6 cmolc dm dm $^{-3}$, saturação por bases: $43 \%$, CTC total: $7,8 \mathrm{cmol}_{\mathrm{c}} \mathrm{DM}^{-3}$; $\mathrm{H}+\mathrm{Al}: 4,4 \mathrm{cmol}_{\mathrm{c}} \mathrm{dm}^{-3}$. O experimento foi conduzido no delineamento de blocos ao acaso em esquema bifatorial (4x3) com parcelas subdivididas. As parcelas principais (Fator A) constaram da rotação entre arroz nãotolerante (IRGA 417) e arroz tolerante aos herbicidas do grupo das imidazolinonas (IRGA 422CL $\left(\right.$ CLEARFIELD $\left.^{\circledR}\right)$. O sistema convencional foi denominado aquele que utilizava a cultivar nãotolerante (IRGA 417) ao herbicida do grupo químico das imidazolinonas. Já o sistema CLEARFIELD ${ }^{\circledR}$ utilizava a cultivar 'IRGA 422CL' que é tolerante ao herbicida do grupo químico das imidazolinonas. Nas safras 2004/05, 2005/06 e 2006/07 houve a seguinte distribuição: (A1) alternância entre o sistema de cultivo com sistema convencional, Sistema CLEARFIELD ${ }^{\circledR}$ e sistema convencional, respectivamente; (A2) Sistema CLEARFIELD $^{\circledR}$ no primeiro ano e nos demais anos sistema convencional; (A3) sistema CLEARFIELD ${ }^{\circledR}$ nos dois primeiros anos e sistema convencional no último ano; (A4) apenas o sistema CLEARFIELD ${ }^{\circledR}$ nas três safras subseqüentes. Nas sub-parcelas foram aplicados os tratamentos para o controle de arroz-vermelho com diferentes épocas de aplicação da mistura formulada de imazethapyr e imazapic contendo $75 \mathrm{~g}$ de imazethapyr e $25 \mathrm{~g}$ de imazapic por litro, onde na testemunha (D1) não foi utilizada nenhuma forma de controle para $o$ arroz-vermelho; (D2) 100g. i.a. ha ${ }^{-1}$ aplicado em pós 
emergência (POS) (dose recomendada para o Brasil); e (D3) $50 \mathrm{~g}$. i.a. ha ${ }^{-1}$ com aplicação em pré-emergência (PRE) somado a 50g. i.a. ha ${ }^{-1}$ aplicado em POS.

Para homogeneizar o banco de sementes de arroz-vermelho, um dia antes da semeadura do arroz, distribuiu-se a lanço e incorporou-se ao solo através de uma grade de dentes a uma profundidade de $5 \mathrm{~cm}$ a quantidade de $200 \mathrm{~kg} \mathrm{ha}^{-1}$ de sementes de arrozvermelho, obtendo-se população média de 260 plantas por metro quadrado.

A semeadura do arroz no primeiro ano ocorreu adotando o sistema convencional de semeadura e nos demais anos o sistema de plantio direto, na densidade de $120 \mathrm{~kg}$ de sementes ha-1 dos genótipos 'IRGA 422 CL' tolerante ao herbicida e o genótipo não-tolerante 'IRGA 417'. A adubação e os demais tratos culturais foram realizados conforme recomendação da pesquisa (SOSBAI, 2003).

A aplicação do herbicida em PRE sobre a genótipo de arroz tolerante, foi realizada um dia após a semeadura (DAS) do arroz tolerante e a aplicação em POS foi efetuada aos 14 dias após a emergência (DAE), quando as plantas de arroz tolerante encontravam-se no início do perfilhamento com quatro folhas no colmo principal estando no estádio V4, e as plantas de arrozvermelho em V5 tendo cinco folhas no colmo principal, segundo escala de COUNCE et al. (2000). Nas 24 horas seguintes após a semeadura ocorreu precipitação pluvial de $53 \mathrm{~mm}, 3 \mathrm{~mm}$ e $130 \mathrm{~mm}$, respectivamente para os três anos, constituindo-se em uma condição favorável para a ativação do herbicida aplicado em PRE. As parcelas testemunhas foram isoladas das demais por placas de PVC.

A fitotoxicidade do herbicida nas plantas de arroz foi realizada através de avaliação visual, em porcentagem, onde zero correspondeu à ausência de fitotoxicidade, e $100 \%$ à morte das plantas. As avaliações foram realizadas aos oito dias após a emergência (DAE) para determinar o efeito do residual do ano anterior e aos 14 dias após a aplicação do herbicida em POS (DAA).

A avaliação do controle de arroz-vermelho foi realizada no dia da colheita, através da comparação entre o tratamento testemunha (sem controle) e os demais tratamentos e a diferenciação do arroz-vermelho do arroz cultivado foi através das características da planta como estatura, arquitetura das plantas e formato dos grãos. Os valores estimados visualmente obedeceram a uma escala de 0 a $100 \%$, onde $0 \%$ correspondeu a ausência de controle e $100 \%$ correspondeu ao controle total das plantas. A produtividade de grãos foi determinada através da colheita manual, em área de $5,25 \mathrm{~m}^{2}(5,0 \times 1,05 \mathrm{~m})$, quando os grãos apresentavam grau de umidade média de $20 \%$.

No primeiro ano os sistemas A2, A3 e A4, foram avaliados como sendo um sistema apenas, pois, todos utilizaram o sistema CLEARFIELD ${ }^{\circledR}$. Da mesma forma, no segundo ano os sistemas A3 e A4 foram avaliados como sendo o mesmo sistema devido à utilização do sistema CLEARFIELD ${ }^{\circledR}$.

Os dados foram submetidos aos testes das pressuposições da análise da variância e em seguida submetidos à análise de variância e ao teste de Tukey (P 0,05) para comparação das médias. Antes da análise dåvariância, os dados de controle de arrozvermelho e fitotoxicidade foram transformados para $y t=\operatorname{arcoseno} \sqrt{(y+0,5) / 100}$.

\section{RESULTADOS E DISCUSSÃO}

\section{Safra 2004/05}

$\mathrm{Na}$ avaliação de fitotoxicidade realizada aos 14DAA da mistura formulada, foram observadas diferenças entre as épocas de aplicação nos sistemas $\mathrm{A} 2, \mathrm{~A} 3$ e A4, tendo as maiores injúrias detectadas no tratamento com aplicação em POS (Tabela 1). No sistema A1 não foram detectadas injúrias em função de ter sido adotado o sistema convencional.

Apesar da dose final ser a mesma entre os tratamentos D2 e D3, os 50g i.a ha ${ }^{-1}$ aplicados em PRE, no tratamento $\mathrm{D} 2$, foram submetidos a um maior período de biodegradação em ambiente aeróbico. Diferentemente desse, após a aplicação da dose em POS, tanto de D2, quanto de D3, a área foi submetida à irrigação contínua, desfazendo-se as condições favoráveis para a biodegradação, reduzindo a atividade dos microorganismos aeróbicos. Segundo FLINT \& WITT (1997), os herbicidas do grupo químico das imidazolinonas são preferencialmente degradados no solo por microorganismos aeróbicos, os quais requerem uma temperatura ótima de $\pm 30^{\circ} \mathrm{C}$ e umidade do solo de aproximadamente $75 \%$ da capacidade de campo. Em função disso, a fitotoxicidade foi substancialmente menor no tratamento PRE+POS. Segundo MARCHESAN et al. (2010) a fitotoxicidade causada pelo imazethapyr é mais severa na aplicação em POS, se comparado à aplicação em PRE. Em condições adversas para o desenvolvimento da cultura, essa fitotoxicidade pode afetar a produtividade de grãos.

Em relação ao arroz-vermelho, foi obtido controle de $98 \%$ nos sistemas que utilizaram CLEARFIELD $^{\circledR}$ (Tabela 2). Ressaltam-se duas práticas de manejo que contribuíram para esse nível de controle: a aplicação da mistura formulada no estádio V4-V5 e a irrigação imediatamente após a aplicação do herbicida em POS, prática essa que proporciona maior disponibilidade e absorção do herbicida pelas plantas. Além disso, a água atua como barreira física para a 
Tabela 1 - Fitotoxicidade em plantas de arroz irrigado aos oito dias após a emergência (oito DAE) (atribuída ao residual) observada aos 383 (2004/05-2005/06) e 358 (2005/06-2006/07) dias da aplicação do herbicida e aos 14 dias após aplicação (DAA) do herbicida em resposta a diferentes sistemas de cultivo em duas épocas de aplicação. Santa Maria-RS, 2010.

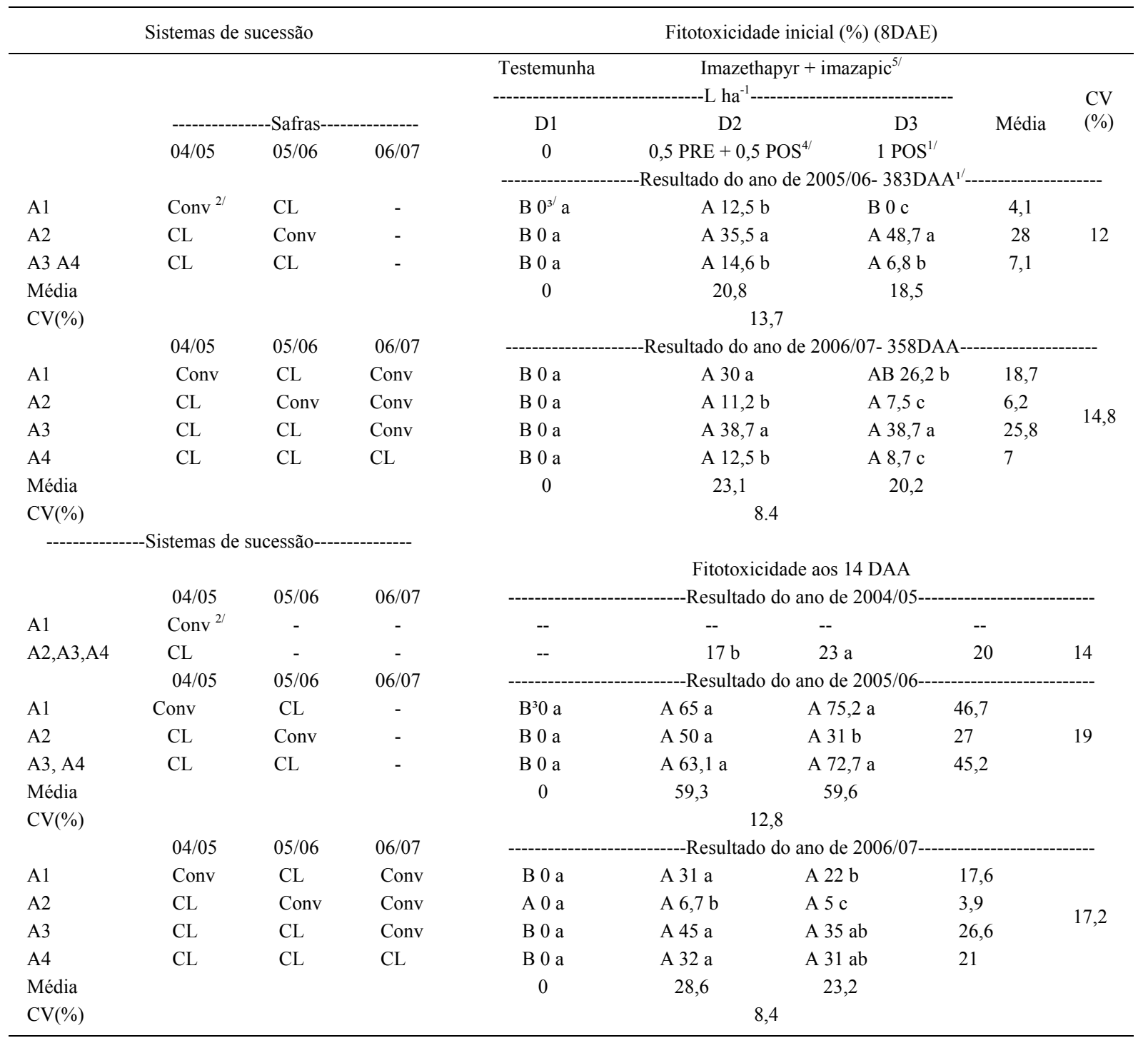

${ }^{1}$ Período entre a aplicação do herbicida e avaliação de fitotoxicidade entre o ano 2004/05 até 2005/06 foi de 383 dias, entre o ano de 2005/06 até o ano de 2006/07 foi de 358 dias e entre o ano de 2004/05 até o ano de 2006/07 foi de 728 dias; ${ }^{2}$ Seqüência dos sistemas de cultivo, que mudam em decorrência do ano (CL- genótipo CLEARFIELD ${ }^{\circledR}$ IRGA 422CL; Conv- Convencional - IRGA 422CL); ${ }^{3}$ Letras diferentes identificam médias diferentes pelo teste de Tukey $(\mathrm{P} \leq 0,05)$;Para cada parâmetro analisado, médias seguidas de letras minúsculas nas colunas referem-se à comparação entre os sistemas e de letras maiúsculas na linha referem-se à comparação entre as épocas de aplicação. ${ }^{4}$ Época de aplicação do herbicida em pré emergência (PRE) e pós emergência (POS). ${ }^{5}$ Mistura formulada de imazethapyr mais imazapic (75 e 25 g i.a. $\left.\mathrm{L}^{-1}\right)$.

emergência das plantas de arroz-vermelho. Como no sistema A1 não foi realizado aplicação do herbicida, o controle de arroz-vermelho e a produtividade não foram determinados devido ao acamamento ocasionado pela grande quantidade de plantas de arroz-vermelho.

Com relação à produtividade de grãos do genótipo 'IRGA 422' CL (Tabela 2), a aplicação do herbicida em POS ou em PRE+POS não apresentou diferença no rendimento de grãos ainda que, na avaliação de fitotoxicidade inicial tenha ocorrido diferenças entre os tratamentos. Esse fato evidencia a capacidade de recuperação das plantas, onde a velocidade com que o herbicida foi metabolizado na planta juntamente com a aplicação na fase inicial de desenvolvimento contribuiu para que os tratamentos com aplicação em POS ou PRE+POS não 
Tabela 2 - Controle de arroz-vermelho (\%), e produtividade de grãos $\left(\mathrm{kg} \mathrm{ha}^{-1}\right)$ em arroz irrigado em resposta a diferentes sistemas de sucessão de cultivos de arroz irrigado e épocas de aplicação de herbicida em três anos agrícolas. Santa Maria-RS, 2010.

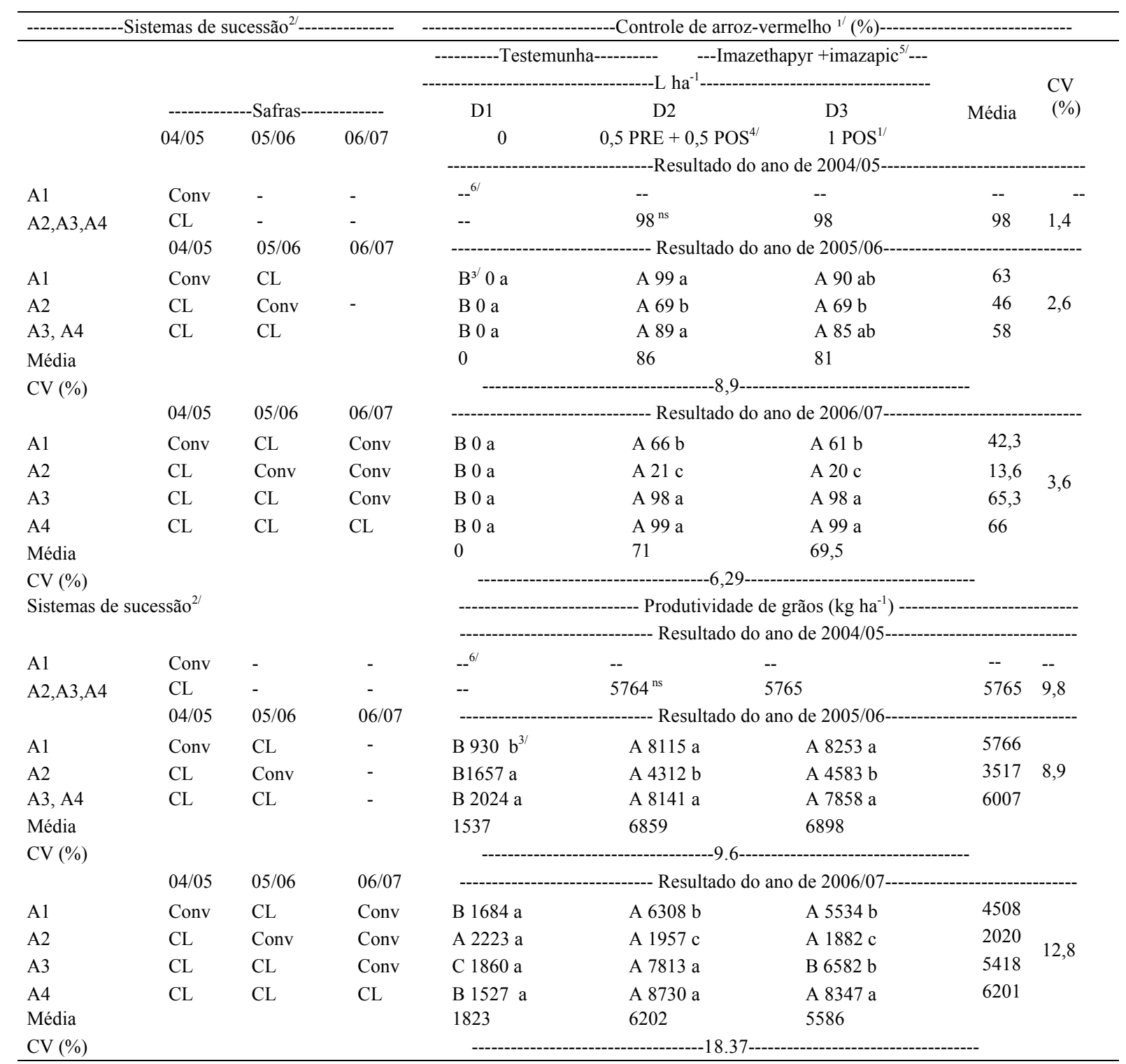

${ }^{1 /}$ Avaliação visual, onde zero correspondeu à ausência de controle, e $100 \%$ de controle das plantas de arroz-vermelho. ${ }^{2 /}$ Seqüência dos sistemas de cultivo, que mudam em decorrência do ano (CL- CLEARFIELD®; Conv- Convencional); ${ }^{3 /}$ Letras diferentes identificam médias diferentes pelo teste de Tukey $(\mathrm{P} \leq 0,05)$;Para cada parâmetro analisado, médias seguidas de letras minúsculas nas colunas referem-se à comparação entre os sistemas e letras maiúsculas na linha referem-se à comparação entre as épocas de aplicação.

4/ Época de aplicação do herbicida em pré emergência (PRE) e pós emergência (POS). ${ }^{5 /}$ Mistura formulada de imazethapyr mais imazapic (75 e 25 g i.a. $\left.\mathrm{L}^{-1}\right){ }^{6 /}$ Dados não mostrados devido à impossibilidade de colheita em virtude do acamamento ocorrido pela alta infestação de arroz-vermelho.

apresentassem diferença significativa na produtividade, fato este também mencionado por KRAEMER et al. (2009b).

\section{Safra 2005/06}

O grau de fitotoxicidade ocasionado pelo efeito residual do herbicida no solo aos 383 DAA no genótipo não-tolerante variou com a dose aplicada e a época de aplicação da mistura formulada. Na avaliação realizada aos $8 \mathrm{DAE}$ as maiores injúrias ocorreram no sistema A2 (CLEARFIELD ${ }^{\circledR}$ seguido de convencional) com a aplicação seqüencial (PRE+POS) ou em POS, os quais não diferiram significativamente entre si (Tabela 1). Já a menor fitotoxicidade foi observada na testemunha sem aplicação, demonstrando a capacidade 
de persistência desse herbicida no solo quando se realizou a aplicação nos respectivos tratamentos.

Em relação às épocas de aplicação, houve diferenças significativas apenas em A1 (convencional seguido de CLEARFIELD ${ }^{\circledR}$ ). Nesse sistema, foi constatada fitotoxicidade de $12,5 \%$ no genótipo tolerante proveniente da aplicação realizada em PRE, a qual diferiu da testemunha e da aplicação em POS (Tabela 1). Isto se deve ao fato de que aos oito DAE ainda não havia sido realizada a aplicação do herbicida em pós-emergência. No sistema onde foi utilizada a tecnologia CLEARFIELD ${ }^{\circledR}$ por dois anos consecutivos (A3), constatou-se menor fitotoxicidade residual no genótipo tolerante no tratamento em POS, realizado na safra anterior. Assim comprova-se mais uma vez a capacidade do herbicida em causar injúrias, mesmo aos 383DAA no genótipo recomendado para uso no sistema CLEARFIELD ${ }^{\circledR}$.

$\mathrm{Na}$ avaliação da fitotoxicidade aos 14DAA na safra 2005/06 foi observado elevadas porcentagens de injúrias no genótipo tolerante cultivado nos sistemas A1 e A3 (todos cultivados no sistema CLEARFIELD $^{\circledR}$ na presente safra) com aplicação do herbicida em POS, com valores diferindo do sistema A2, o qual não recebeu aplicação do herbicida (Tabela 1).

No sistema A2, as injúrias causadas ao genótipo não-tolerante foram decorrentes da aplicação do herbicida na safra anterior (383DAA) com valores de $50 \%$ de fitotoxicidade quando se aplicou em $\mathrm{PRE}+\mathrm{POS}$ reforçando o fato da capacidade do produto em persistir no solo e de causar fitotoxicidade às culturas não-tolerantes.

Algumas considerações são necessárias para justificar a maior fitotoxicidade observada no experimento. O período de entressafra do arroz no RS caracteriza-se por condições de baixa temperatura, o que contribuiu para a diminuição da atividade microbiana (FLINT \& WITT, 1997). Aliado a isto, o pH do solo era de 5,0 sendo que valores menores que estes ocasionam aumento da adsorção da molécula dos herbicidas aos colóides do solo, indisponibilizando-as para a biodegradação (KRAEMER et al., 2009a). Além disso, os teores de M.O nas condições do experimento, em torno de $1,6 \%$ e $20 \%$ de argila, contribuem para a permanência da molécula do herbicida no solo. Sabese que a permanência das moléculas de imidazolinonas estão diretamente relacionadas com a quantidade de matéria orgânica, argila e pH do solo (LOUX \& REESE, 1992), sendo que esses fatores podem estar diretamente relacionados com a permanência do herbicida e a fitotoxicidade às plantas, encontradas no experimento.

Com a irrigação do arroz na safra há maior disponibilidade dos herbicidas na solução do solo, visto que segundo AVILA et al. (2006), quando o solo encontra-se na capacidade de campo, $61 \%$ de imazethapyr estaria na solução do solo, ao passo que com a saturação essa quantidade aumentaria para $73 \%$. Além disso, aproximadamente 20 dias após a irrigação, ocorre o fenômeno chamado "auto calagem", que eleva o pH de solos ácidos favorecendo a dissociação das moléculas do herbicida, predominando a forma aniônica, a qual é repelida pelas cargas negativas das argilas e das superfícies orgânicas, passando então para a solução do solo e tornando-se passível de ser transportada ou absorvida pelas plantas (CHE, 1992) causando danos de fitotoxicidade as plantas de arroz.

$\mathrm{Na}$ avaliação sobre controle de arrozvermelho, observa-se que a utilização do sistema CLEARFIELD $^{\circledR}(\mathrm{A} 1, \mathrm{~A} 3)$ obteve controle de aproximadamente $90 \%$, comparado com $69 \%$ do sistema convencional (A2) (Tabela 2). O menor controle de arroz-vermelho (90\%) no sistema CLEARFIELD ${ }^{\circledR}$, comparado à safra anterior (98\%), pode ter sido influenciado pela drenagem da área realizada para viabilizar o estabelecimento do arroz semeado, no sentido de evitar danos causados pelos ácidos orgânicos produzidos durante a decomposição da matéria seca do azevém cultivado na entressafra.

Em relação à produtividade, os melhores resultados foram alcançados com a utilização do sistema CLEARFIELD $^{\circledR}(\mathrm{A} 1, \mathrm{~A} 3)$ (Tabela 2). No entanto, o uso do sistema convencional após a adoção do sistema CLEARFIED $^{\circledR}$ no ano anterior proporcionou diminuição da produtividade, provavelmente em decorrência da soma dos efeitos da fitotoxicidade ocorrida no genótipo não-tolerante em função do residual no solo do herbicida aliado ao baixo nível de controle de arroz-vermelho.

\section{Safra 2006/07}

Novamente, constatou-se capacidade de persistência do herbicida pertencente ao grupo químico das imidazolinonas. Após o intervalo de 358 dias entre a aplicação e a semeadura do genótipo não-tolerante, o efeito residual, constatada pela fitotoxicidade aos oito DAE, mostrava-se evidente (A1 e A3), tanto na aplicação em POS quanto na aplicação sequencial (Tabela 1). Para o sistema com dois anos consecutivos de CLEARFIELD ${ }^{\circledR}$ (A3) a condição de fitotoxicidade parece ser potencializada, o que pode indicar uma condição de acumulação desse herbicida durante os anos. Transcorridos 728DAA do herbicida para o genótipo não-tolerante apresentou fitotoxicidade de 7,5 e $11,2 \%$ na aplicação em POS e PRE+POS, respectivamente. A avaliação de fitotoxicidade aos 14DAA na safra 2006/07apresentou a mesma tendência 
do ano anterior, onde a maioria dos tratamentos com aplicação de herbicida diferiram da testemunha.

A utilização do sistema convencional após dois anos consecutivos do sistema CLEARFIELD $^{\circledR}(\mathrm{A} 3)$ potencializou os valores de fitotoxicidade, porém o fracionamento da dose não diferiu estatisticamente daquele que utilizou o sistema convencional após um ano de sistema CLEARFIELD ${ }^{\circledR}$ (A1), embora a fitotoxicidade encontrada em valores absolutos tenha sido menor.

Os resultados do terceiro ano de controle de arroz-vermelho (Tabela 2) demonstram o sistema que utilizou dois anos de convencional após o sistema CLEARFIELD $^{\circledR}$ (A2) foi o que apresentou maior incidência de arroz-vermelho. Isto demonstra a ineficácia da utilização de apenas um ano do sistema CLEARFIELD ${ }^{\circledR}$ em área com alta infestação de arrozvermelho, pois provavelmente esse produto não atua no banco de sementes. A utilização consecutiva do sistema CLEARFIELD ${ }^{\circledR}$ (A4) possibilitou média de 99\% de controle, resultado semelhante ao sistema que utilizou dois anos de CLEARFIELD ${ }^{\circledR}$ seguido do sistema convencional (A3). Isso demonstra que a utilização de dois anos consecutivos de CLEARFIELD ${ }^{\circledR}$ reduz substancialmente a emergência de arrozvermelho, porém esse nível de controle possibilita que com o passar dos anos o cultivo intensivo e continuado das áreas, ocasione a reinfestação e o cruzamento entre o arroz tolerante e o arroz-vermelho.

Os resultados de produtividade estão relacionados diretamente à incidência de arrozvermelho. Os sistemas que apresentaram menor incidência foram os que apresentaram maior produtividade de grãos. Em contrapartida, a não utilização do CLEARFIELD ${ }^{\circledR}$ acarreta elevada infestação de arroz-vermelho com conseqüências diretas sobre a diminuição da produtividade.

\section{CONCLUSÃO}

A mistura formulada de imazethapyr e imazapic utilizada para o controle de arroz-vermelho em solos de várzea apresenta capacidade de permanecer no solo em doses que podem causar fitotoxicidade em genótipos não-tolerantes e tolerantes utilizados em sucessão.

O controle do arroz-vermelho é eficiente com a utilização do sistema CLEARFIELD ${ }^{\circledR}$ entretanto, a utilização de apenas um ano deste sistema não permite a redução ou eliminação do banco de sementes de arrozvermelho. O melhor nível de controle e produtividade é obtido após dois ou três anos consecutivos da utilização do sistema CLEARFIELD ${ }^{\circledR}$.

\section{AGRADECIMENTO}

Ao Conselho Nacional de Desenvolvimento Científico e Tecnológico (CNPq), pela concessão de bolsa aos autores Enio Marchesan e Luis Antonio de Avila.

\section{REFERÊNCIAS}

ALISTER, C., KOGAN M. Efficacy of imidazolinone herbicides applied to imidazolinone-resistant maize and their carryover effect on rotational crops. Crop Protection, v.24, n.4, p.375379, 2005. Disponível em: <http://www.sciencedirect.com/ science?_ob=MImg\&_imagekey=B6T5T-4DXBSSN-1 $4 \&$ \&cdi $=5011 \&$ user $=687358 \&$ \& ii $=$ S0261219404002339\& origin $=$ browse\&_zone $=$ rslt list item\&_coverDate $=04 \% 2 \mathrm{~F} 01 \%$ 2 F $2005 \&$ s k $=999759995 \&$ w c h p $=$ d G L b V l z zSkzS\&md5=e927e8e7a8f97e48864c55af5d3f9966\&ie=/ sdarticle.pdf $>$. Acesso em: 07 nov. 2010. doi:10.1016/ j.cropro.2004.09.011.

AVILA L.A, et al. Imazethapyr aqueous photolysis, reaction quantum yield, and hydroxyl radical rate constant. Journal Agriculture Food Chemistry, v.54, n.7, p.2635-2639, 2006.

BAUGHMAN, T.A.; SHAW, D.R. Effect of wetting/drying cycles on dissipation patterns of bioavailable imazaquin. Weed Science, v.44, n.2, p.380-382, 1996. Disponível em: $<\mathrm{http}: /$ /pubs.acs.org/doi/full/10.1021/jf052214b>. Acesso em: 07 nov. 2010. doi: $10.1021 / \mathrm{jf052214b}$.

CHE M. et al. Effect of $\mathrm{pH}$ on sorption and desorption of Imazaquin and Imzethapyr on clays and humic acid. Journal Environmental Quality, v.21, n.4, p. 698-703, 1992. Disponível em: <https://www.crops.org/publications/search?search[$3]=\& \operatorname{searchType}[-3]=$ Any \& search [-2] $=$ che\&searchFields[2][Author]=Author\&search Type [-2]=Phrase\&search [$1]=\& \operatorname{searchFields}[-1][$ Title] $=$ Title $\&$ search Type[$1]=\mathrm{Phrase} \& \mathrm{volume}=21 \&$ is sue $=\&$ ye ar $=1992 \&$ first page $=\&$ journal[jeq] $=$ jeq\&search $[0]=>$. Acesso em: 07 nov. 2010 . doi:10.2134/jeq1992.214698x.

CLAY, D.V. Herbicide residues in soils and plants and their bioassay. In: STREIBIG, J.C.; KUDSK, P. Herbicide bioassays. Florida: CRC, 1993. p.153-171.

COUNCE, P.A. et al. A uniform, objective, and adaptive system for expressing rice development. Crop Science, v.40, p.436-443, 2000. Disponível em: <http://crop.scijournals.org.w10050.dotlib.com.br/cgi/ content/full/40/2/436>. Acesso em: 28 mar. 2009.

COX, C. Imazapyr: herbicide factsheet. Journal of Pesticide Reform Imazapyr, v.16, n.3, p.16-20, 1996.

EMBRAPA. Centro Nacional de Pesquisa de Solos. Sistema brasileiro de classificação de solos. Brasília: Embrapa Rio de Janeiro, 2006. 306p.

FLINT, J.L.; WITT, W.W. Microbial degradation of imazaquin and imazethapyr. Weed Science, v.45, p.586-591, 1997.

GRYMES, C.F. Response of soybean (Glycine max) and rice (Oryza sativa) in rotation to AC 26222. Weed Tecnology, v.9, p.504-511, 1995. 
KRAEMER A.F. et al. Destino ambiental dos herbicidas do grupo das imidazolinonas - revisão. Planta daninha, v.27, n.3, p.629-639, 2009a. Disponível em: <http:// www.scielo.br/scielo.php? script $=$ sci_arttext\&pid $=\mathrm{S} 0100$ $83582009000300025 \& \operatorname{lng}=\mathrm{pt} \& \mathrm{nrm}=\mathrm{iso}>$. Acesso em: 07 nov. 2010. doi: 10.1590/S0100-83582009000300025.

KRAEMER A.F. et al. Lixiviação do imazethapyr em solo de várzea sob dois sistemas de manejo. Ciência Rural, v.39, n.6, p.1600-1666, 2009b. Disponível em: <http://www.scielo.br/ scielo.php? script=sci arttext\&pid=S 0103 $84782009000600005 \& \operatorname{lng}=$ pt\&nrm=iso $>$. Acesso em: 07 nov. 2010. doi: 10.1590/S0103-84782009005000119.

LOUX, M.M.; REESE, K.D. Effect of soil $\mathrm{pH}$ on adsorption and persistence of imazaquin. Weed Science, v.40, n.3, p.490496, 1993.

MARCHESAN E. et al. Carryover of imazethapyr and imazapic to nontolerant rice. Weed Technology, v.24 p.6-10, 2010.
Disponível em: <http://www.bioone.org/doi/full/10.1614/WT08-153.1>. Acesso em: 07 nov. 2010. doi: 10.1614/WT-08153.1 .

PEREZ, K.S.S. et al. Nitrogênio da biomassa microbiana em solo cultivado com soja, sob diferentes sistemas de manejo, nos Cerrados. Pesquisa Agropecuária Brasileira, v.40, n.2, p.137-144, 2005. Disponível em: <http://webnotes.sct.embrapa.br/pab/pab.nsf/ FrAnual>. Acesso em: 07 nov. 2010. doi: 10.1590/S0100204X2005000200006.

SOCIEDADE SUL-BRASILEIRA DE ARROZ IRRIGADO (SOSBAI). Arroz irrigado: recomendações técnicas da pesquisa para o Sul do Brasil. Pelotas, RS: SOSBAI, 2007. $159 \mathrm{p}$.

STOUGAARD, R.N. et al. Effect of soil type and $\mathrm{pH}$ on adsorption, mobility and efficacy of imazaquin and imazethapyr. Weed Science, v.36, n.1, p.67-73, 1990. 